Int. J. Dev. Biol. 58: 889-894 (2014)

doi: $10.1387 / \mathrm{ijdb} .140239 \mathrm{db}$

\title{
Amniote yolk sacs: diversity in reptiles and a hypothesis on their origin
}

\author{
RICHARD P. ELINSON ${ }^{1}$, JAMES R. STEWART ${ }^{2}$, LAURIE J. BONNEAU ${ }^{3}$ and DANIEL G. BLACKBURN ${ }^{*, 3}$ \\ 1240 West Neck Road, Huntington, NY, ${ }^{2}$ Department of Biological Sciences, East Tennessee State University, \\ Johnson City, TN and ${ }^{3}$ Department of Biology, and Electron Microscopy Center, Trinity College, Hartford, CT, USA
}

\begin{abstract}
Oviparous amniotes produce a large yolky egg that gives rise to a free-living hatchling. Structural characteristics and functional attributes of the egg are best known for birds, which have a large mass of fluid yolk surrounded by an extraembryonic yolk sac. Yolk nutrients are delivered to the embryo via the vascular yolk sac. This developmental pattern and nutrient transport mechanism is thought to be representative of all other lineages of amniotes. Recent discovery of a snake with cellularized yolk organized around a meshwork of blood vessels reveals an additional pattern for yolk mobilization, which may also occur in other squamate reptiles (lizards and snakes). This complex yolk sac raises interesting questions about developmental mechanisms and suggests a possible model for the transition between the egg of anamniotes and that of amniotes.
\end{abstract}

KEY WORDS: cleavage, yolk, embryo maintenance, yolk sac, oviparity

\section{Introduction}

Vertebrates became completely terrestrial with the evolution of the amniotic egg. The primary innovation of the egg is a large supply of yolk that allowed amniote embryos to develop on land and to hatch as miniature adults (Packard and Seymour, 1997). This life history pattern emerged because of innovations to separate the large mass of yolk from the embryo proper during early development and to form extraembryonic tissues to provide respiratory and nutrient transport support to the embryo during later development. Understanding the likely characteristics of the transition to the pattern of development of the oviparous amniotic egg has been hampered by limited information, particularly for oviparous amniotes. The primary source of information on cleavage and yolk sac development in oviparous amniotes comes from studies of birds, principally the domestic chicken (Bellairs et al., 1978; Lee et al., 2013). In chickens, the embryo develops from a small disc of cells resting on top of a large mass of yolk in a process termed meroblastic cleavage. The yolk component of the zygote does not divide into cells and forms a large fluid mass, which is surrounded by an outgrowth of the embryo, the vascular yolk sac. This pattern of development is the model for oviparous amniotes, although variations on this theme are recognized among the major lineages (Stewart, 1997).

A recent discovery that the yolk of the corn snake, Pantherophis guttatus, becomes cellularized and forms a solid, vascularized tissue (Elinson and Stewart, 2014) reveals a dramatic contrast to the development of the yolk sac of the chicken that raises questions regarding appropriate models for the egg of early amniotes. We will consider the relevance of development of the corn snake yolk sac to other squamates, and amniotes generally, and suggest a new scenario for the evolution of the yolk sac of oviparous amniotes.

\section{Cleavage patterns}

Vertebrate yolk, containing nutrients to support embryonic development, is incorporated into the cytoplasm of the egg cell during late stages of oogenesis. Yolk content determines embryonic size until additional external sources are available. Variation in egg size is primarily determined by yolk content and egg size constrains cleavage patterns (reviews in Collazo et al., 1994; Elinson, 2009; Collazo and Keller, 2010). In vertebrates with relatively smalleggs, cleavage is holoblastic. Early furrows extend through the entire zygote and subsequent cell divisions result in cells of roughly equal size. Variation in early cleavage patterns among anamniotes with holoblastic cleavage is influenced by egg size (Collazo and Keller, 2010). Yolk is enclosed within cells during holoblastic cleavage, but may be either intra-embryonic or extra-embryonic (Takeuchi et al., 2009). The evolution of large eggs with meroblastic cleavage has occurred in at least four lineages of anamniotes, in addition to amniotes (Collazo et al.,

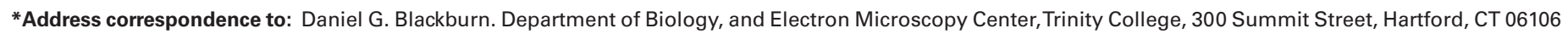
USA. E-mail: Daniel.Blackburn@trincoll.edu -Web: http://commons.trincoll.edu/blackbur

Accepted: 19 December 2014.

ISSN: Online 1696-3547, Print 0214-6282

(C) 2014 UBC Press

Printed in Spain 

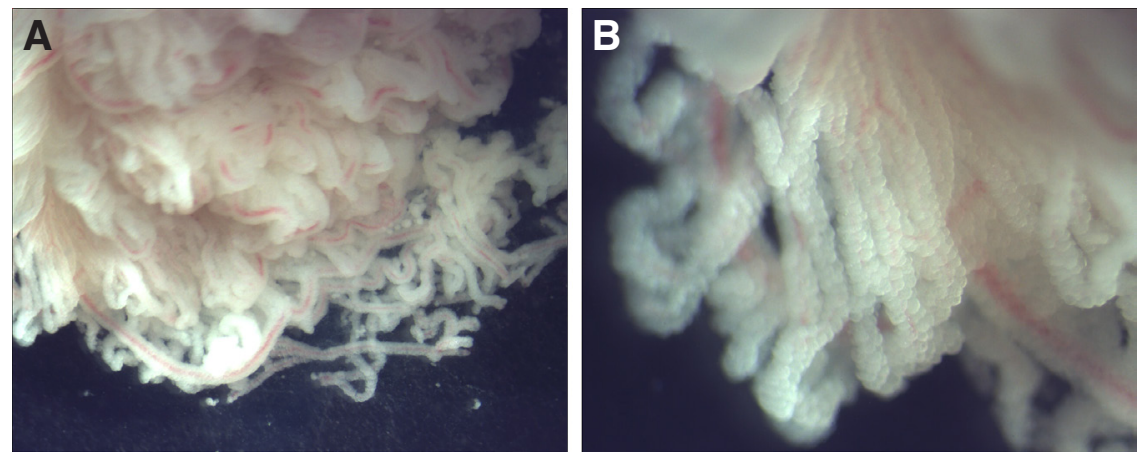

Fig. 1. Morphology of the yolk sac of corn snakes (Pantherophis guttatus). (A) The corn snake yolk sac, dissected at stage 34, is a spaghetti-like mass with blood vessels covered by yolk-rich endodermal cells. (B) Higher magnification shows endodermal cells attached to the blood vessels.

1994; Elinson, 2009; Collazo and Keller, 2010). Vertebrates with meroblastic cleavage generally have yolk that is extraembryonic and not enclosed in multiple cells.

\section{Yolk sac structure of amniotes}

Mechanisms to metabolize and transport nutrients from extraembryonic yolk differ among vertebrates with meroblastic cleavage. Amniotes evolved a suite of extraembryonic tissues, among them a vascular yolk sac, which actively participates in mobilization of yolk. The evolutionary changes of increased yolk, meroblastic cleavage, and extraembryonic membranes are linked to each other. Yolk is simply a nutritional storage form to be used by the embryo, but a large amount of yolk interferes with cleavage. Eliminating cell divisions in the yolk rich region of the zygote has the advantages of reducing metabolic activities and cellular syntheses. If yolk is not contained within cells, there must be a means to utilize the nutrition in the yolk, and that is provided by the vascular yolk sac, composed of an endodermal epithelium facing the yolk and an outer mesodermal epithelium with associated blood vessels. Metabolites derived from yolk are taken up by endodermal cells and transferred to blood vessels for distribution throughout the embryo.

Various scenarios have been proposed for the sequence of appearance of increased yolk, meroblastic cleavage, and extraembryonic membranes among early amniotes (Elinson, 1989; Packard and Seymour, 1997; Stewart, 1997; Arendt and Nubler-Jung, 1999; Elinson and Beckham, 2002), but there is unlikely to be a fossil record to test these proposals given the delicate nature of embryonic soft tissues. A potential source of evidence is a comparison of yolk sacs and other extraembryonic membranes in extant amniotes. Development and structure of the yolk sac has been studied in all major amniote lineages, but among oviparous species is best known in birds, mainly in chickens (Hamilton, 1952; Romanoff, 1960). Early stages of yolk sac development are conserved and thus similar in turtles, lizards and snakes, crocodilians and birds (Stewart, 1997).

The primary yolk sac (bilaminar omphalopleure) forms in all oviparous amniotes as an outgrowth of endoderm and ectoderm from the blastodisc, which envelops the large mass of yolk. A sheet of mesoderm subsequently extends between layers of the bilaminar omphalopleure forming the non-vascular trilaminar omphalopleure (ectoderm, mesoderm, and endoderm). Blood vessels organize within the mesoderm and hematopoietic sites contribute the first blood cells to the developing embryo. Thus, the non-vascular trilaminar omphalopleure is transformed into the vascular trilaminar omphalopleure, also termed the choriovitelline membrane. As the choriovitelline membrane grows around the circumference of the egg, the sheet of mesoderm, forming the middle layer of the tissue, begins to split, initially in the region of the embryo. The resulting cavity, an extraembryonic coelom, extends toward the abembryonic hemisphere of the egg and divides the choriovitelline membrane into two layers. The outer layer, composed of ectoderm and mesoderm, lies adjacent to the eggshell and is termed the chorion, which is not vascularized. The inner layer of mesoderm and endoderm forms the splanchnopleuric yolk sac. Blood vessels associated with the original mesodermal layer of the choriovitelline membrane provide vascular support for the yolk sac. This structure surrounds the yolk sac cavity of all oviparous amniotes as the "definitive" yolk sac. In birds, endodermal cells occur only in the splanchnopleuric yolk sac, but these cells occur throughout the yolk sac cavity in corn snakes and perhaps other squamates, as described below.

\section{Cellularization of the corn snake yolk sac}

Everyone is familiar with chicken eggs, so the term 'yolk sac' usually conjures up an image of a bag of viscous, liquid yolk. This image is indeed correct for the developing chicken embryo, and
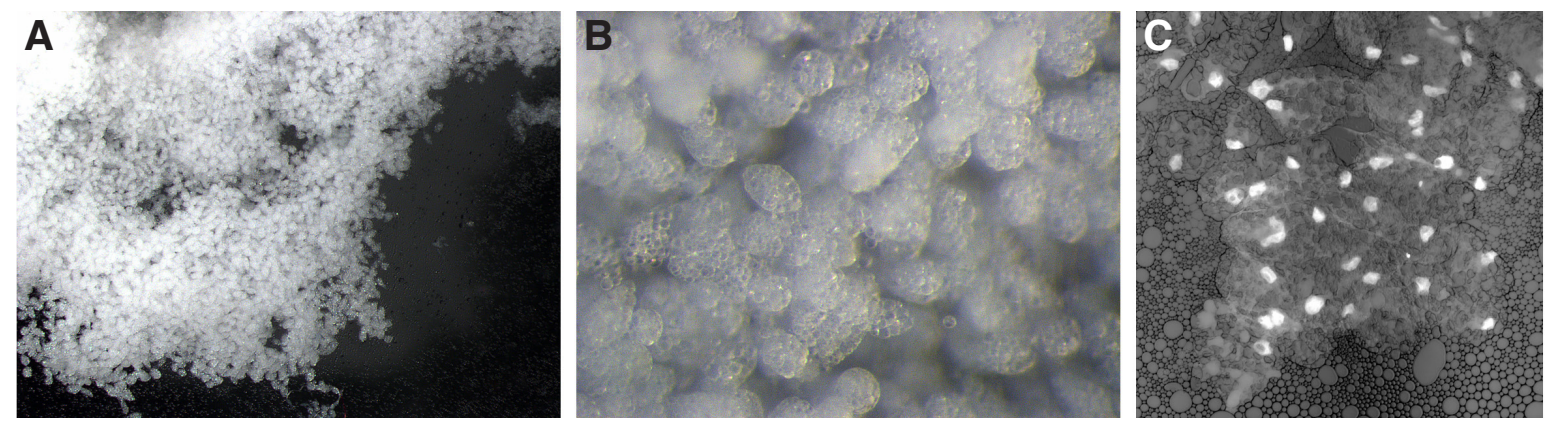

Fig. 2. Yolk sac endodermal cells in the corn snake. (A) Within the yolk sac at stage 25/26, there are large numbers of endodermal cells. (B) $A$ higher magnification of these cells shows the yolky lipid inclusions. (C) DAPI staining at stage 23/24 shows the nuclei of the yolk-rich endodermal cells, isolated from the yolk sac. The cells are surrounded by lipid droplets. 

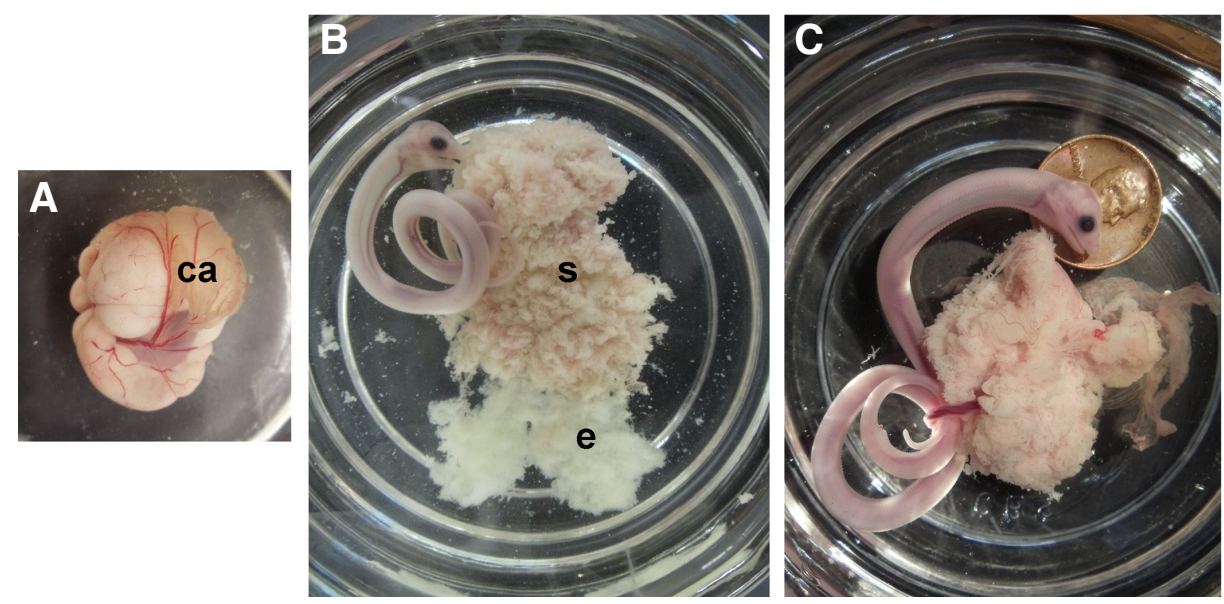

Fig. 3. Corn snake yolk sac. (A) At stage 31, the embryo is sunk into the yolk sac, as seen in this isolate removed from the shell. There are blood vessels in the chorioallantoic membrane (ca) and on the surface of the yolk sac. (B) Dissection of the isolate shows the embryo, the spaghetti-like mass of decorated blood vessels (s), and endodermal cells (e), not yet associated with blood vessels. (C) A later embryo (Zehr stage 34) is attached to the spaghetti-like mass of yolk sac tissue by the yolk sac stalk.

it is generally considered that yolk sacs in other birds and reptiles are probably similar to that of the chicken. That may not be the case. Elinson and Stewart (2014) recently reported that the yolk sac of the corn snake (Pantherophis guttatus) (Colubridae) eventually becomes a mass of spaghetti-like blood vessels coated by large endodermal cells (Fig. 1). There is no non-cellular yolk late in development; it is all contained within the endodermal cells.

Corn snake development takes far longer than the three weeks of chicken development before hatching. Eggs are laid 50-60 days after mating, and hatching of the snake from the egg occurs 10-14 weeks after laying (depending on temperature) (Knight and Blackburn, 2008). At the time of oviposition, the embryo already exhibits the body form of a snake (stage 22: Zehr, 1962), and most of the yolk is non-cellular. By stage 23/24, there is a mass of yolk-rich endodermal cells near the embryo, indicating that parceling the yolk into cells has begun (Fig. 2C). Over the next month, there is less non-cellular yolk. More and more yolk-rich cells are present (Fig. 2), and the mass of yolk-rich cells is invaded by blood vessels from the yolk sac splanchnopleure. Yolk-rich cells attach to the blood vessels, producing the spaghetti-like mass, and the entire yolk sac has this appearance by about two months after laying (Fig. 3).

These observations raise many developmental questions. First, there may be an unusual pattern to the nuclear and cell divisions, given the large amount of yolk-rich cytoplasm. For example, there is initially a syncytium in the central region of the yolky fruit fly egg (Mazumdar and Mazumdar, 2002). Nuclei are present in the cytoplasm and are not surrounded individually by cell membranes. Only later do membranes form. In both fruit fly and chicken eggs (Lee et al., 2013), nuclei at the surface are surrounded initially by only apical and lateral cell membranes with delayed formation of the complete membrane. A syncytial pattern like one of these is likely to be present in corn snake yolk sac.

Second, in order to form cells in the yolk, there must be cell cycle regulators, such as cyclins, as well as structural proteins, such as microtubules, lamins, histones, and membrane proteins. It is not known when and where these molecules are synthesized. Given the large size of the yolk $(\sim 10 \mathrm{ml})$, some of these molecules may be placed in the yolk during oogenesis and stored as RNAs or proteins. This would necessitate a very long-term storage, since yolk cellularization occurs months after oogenesis is completed. Alternatively, the nuclei present in the yolk-rich cytoplasm may be transcriptionally active. Some mechanisms would have to be present to keep any new RNAs and proteins from diffusing through the yolk mass, so that they can function near the nuclei.

Athird developmental question is what stimulates invasion of the yolk-rich endodermal cells by blood vessels. Growth of blood vessels into a region is promoted by angiogenic factors, such as VEGF-A, VEGFR2, and HIF1 $\alpha$ (Risau, 1997; Gilbert, 2010), and formation of blood vessels in embryos depends on signals from the endoderm (Wilt, 1965; Vokes and Krieg, 2002; Jin et al., 2005). This suggests the possibility that the invasion of the yolk-rich endodermal cells by blood vessels is due to angiogenic factors secreted by those cells. As with the question of cell cycle proteins, that requires that the yolk-rich endodermal cells be transcriptionally active.

\section{Is the corn snake pattern shared by other reptiles?}

The vascularized, cellularized yolk sac of corn snakes may be a derived character for the corn snake lineage. Alternatively, it may be a basal condition for a larger group such as squamates or even reptiles. If it is basal for Reptilia, the non-cellularized chicken yolk sac would then be relegated to a derived condition. There are a few hints that other squamate reptiles have a yolk sac like
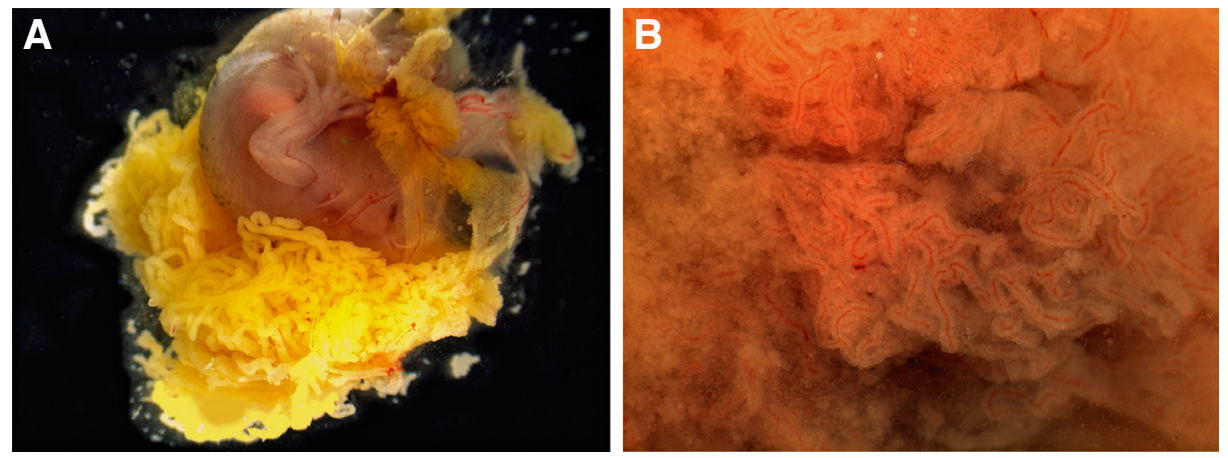

Fig. 4. Cellularized yolk in squamates. (A) In the Eastern fence lizard (Sceloporus undulatus), stage 34 (as per Dufaure and Hubert, 1961), there are spaghetti-like strands with cellularized yolk. (B) The king snake (Lampropeltis getula), stage 32 (Zehr, 1962) also has strands of cellularized yolk occupied by vitelline capillaries. 


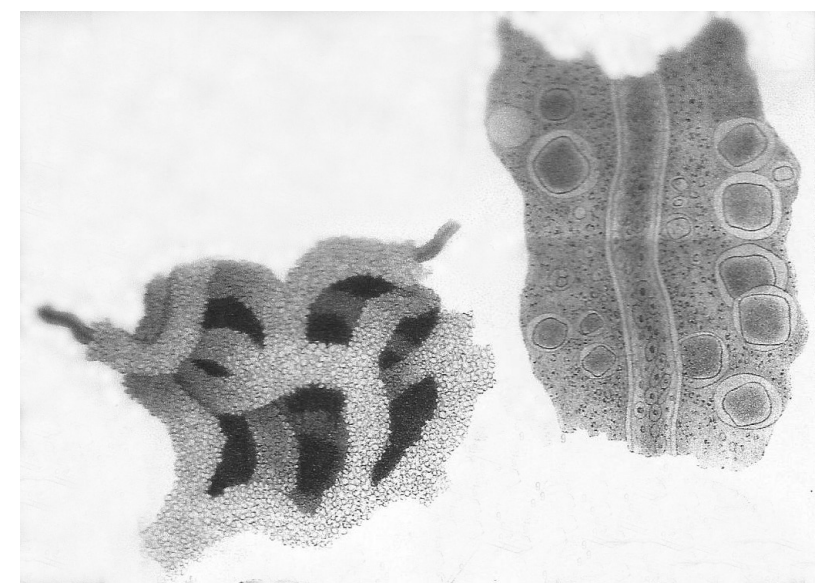

Fig. 5. Snapping turtle yolk sac. A drawing (left) by H.J. Clark shows a meshwork of blood vessels, coated by yolk, in the yolk sac of a snapping turtle hatchling. At a higher magnification (right), a blood vessel is depicted relative to the yolk. These drawings are from Figures 4 and 4a, Plate II, Volume II, in Agassiz (1857).

the corn snake.

Observations on the Eastern fence lizard Sceloporus undulatus (Phrynosomatidae) reveals similarities to the corn snake. In this oviparous species, eggs are laid at the early limb bud stage (stage 27 in the Dufaure and Hubert [1961] system), as is typical of squamates (Blackburn, 1995). At oviposition, the yolk mass is non-cellular. It becomes progressively cellularized during development. By late development, yolky cells of the endoderm coat the vitelline vessels in a meshwork (Fig. 4A) as in the corn snake. A similar pattern characterizes the oviparous California king snake, Lampropeltis getula (Colubridae). Throughout incubation, the yolk material in this species is progressively cellularized. By later developmental stages, the vitelline mass consists of elongate strands formed of endodermal cells that surround vitelline capillaries (Fig. 4B). A meshwork also develops in the yolk of the lizard Podarcis sicula (Lacertidae) (Romano et al., 2002). The presence of yolkfilled endodermal cells associated with blood vessels within the yolk sac cavity also has been described in the family Scincidae in both a viviparous species (Weekes, 1927) and an oviparous one (Stewart et al., 2012).
While few in number, the six squamate species in which cellularized yolk has been observed represent four families that are broadly distributed phylogenetically (Sites et al., 2011). If the yolk sac meshwork is generally found in lizards and snakes, as this distribution suggests, then it likely represents a basal character for squamates.

Tracing origins of this feature beyond squamates is hampered by the fact that information on other reptiles is extremely sketchy (Stewart, 1997). There is an intriguing set of drawings, however, of a meshwork in a late snapping turtle embryo in Agassiz's famous Contributions to the Natural History of the United States (1857) (Fig. 5). These figures suggest that the yolk sac becomes cellularized in a turtle, although the resolution in the drawings is not sufficient to define cells.

Beyond the scientific value, there is an interesting story behind the figures. Most of the drawings of turtle embryos, including the yolk sac, were done by Henry James Clark, based on his own observations. Many of the embryological descriptions were apparently written by Clark as well, but Agassiz did not include Clark as an author. Clark complained bitterly about this lack of recognition, even to the extent of publishing a small pamphlet (Clark, 1863) and including several pages of explanatory footnotes in his book (Clark, 1865). Clark lost his position at Harvard as a result of this controversy, and spent a decade wandering between academic positions (Packard, 1877; Lurie, 1988; Winsor, 1991; Irmscher, 2013). He died at the early age of 47.

\section{A new hypothesis for the origin of the amniote yolk sac}

The evolutionary transition from holoblastic to meroblastic cleavage is a rare event for vertebrates. It occurred stably 4-5 times among aquatic vertebrates, but only once among terrestrial vertebrates (Collazo et al., 1994; Elinson, 2009). That one event was in the lineage leading to amniotes. Cleavage is a very early event in embryogenesis, so an increase in yolk with a concomitant transition to meroblastic cleavage could have been an early event in the evolution of the amniote egg. The results from corn snakes suggest a new possibility for an initial event in the formation of this evolutionary novelty, namely the invasion of yolk-rich endodermal cells by blood vessels. This invasion allowed the later transition to meroblastic cleavage.
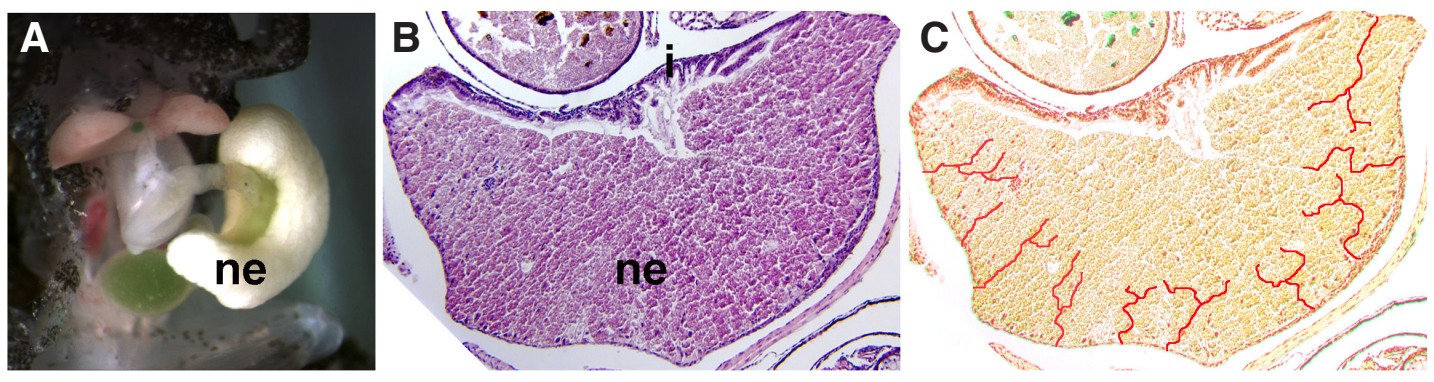

Fig. 6. Hypothesis on the origin of the amniote yolk sac. The last common ancestor between amphibians and amniotes is considered to have a large, yolk-rich egg that cleaves holoblastically. The direct developing frog Eleutherodactylus coqui with yolk-rich, $3.5 \mathrm{~mm}$ eggs, mimics this condition. (A) In E. coqui, the yolky region cellularizes and forms the nutritional endoderm (ne). The nutritional endoderm is attached to the small intestine, as seen in this dissection of a hatched froglet. There are blood vessels in the splanchnopleure surrounding the nutritional endoderm, which provides a means to transport nutrition to the embryo's body, but the blood vessels do not invade the endoderm. (B) A section through the gut of the hatchling shows intestinal tissue (i) attached to a mass of yolk-rich cells of the nutritional endoderm. (C) Invasion of the yolk-rich cell mass by blood vessels is a hypothetical transitional form from the nutritional endoderm to a corn snake type of yolk sac. (A, B) are from Buchholz et al., 2007). 
Starting with the developmental pattern in all basal rhipidistian (lungfish + amphibian) embryos, the yolk-rich region of the egg is divided into cells, and this mass of endodermal cells is surrounded by mesoderm during gastrulation. Blood vessels develop in the mesoderm, but they do not invade the endodermal mass. Yolk in the endodermal cells is broken down, and must in some way be transported to the blood vessels for distribution to the embryo's body. In the model amphibian Xenopus laevis, the endodermal cells, depleted of yolk, differentiate into gut and associated organs (Chalmers and Slack, 2000). A deviation from this pattern is present in the Puerto Rican tree frog, Eleutherodactylus coqui, whose egg is 20x larger than that of $X$. laevis due to an increased yolk supply. Most of the yolk-rich cells are part of the nutritional endoderm (Fig. 6) (Buchholz et al., 2007; Elinson, 2009). Once their yolk is depleted, the cells disappear from the embryo and do not contribute to any differentiated tissues. Development from a large egg in E. coqui is derived, but a recent phylogenetic analysis suggests that development from large, yolky eggs is an amphibian ancestral trait (Desnitskiy and Litvinchuk, 2014)

If the mass of yolk-rich cells in amphibian embryos were invaded by blood vessels (Fig. 6C), those blood vessels would likely provide a more efficient system for moving yolk metabolites to the body of the embryo. They also would provide a system for gas exchange, deep within the endodermal mass. Acquisition of these two improvements in function would permit accumulations of much more yolk in the egg, which in turn gives the advantage of generating a much larger embryo with a higher survival probability upon hatching. Further increases in yolk would be facilitated by a transition from holoblastic to meroblastic cleavage. There would then be no need to expend resources and time to divide the yolk into cells during early embryogenesis. In this scenario, the initial event in the evolution of the yolk sac was the invasion of the mass of yolk-rich endodermal cells by blood vessels. The later transition from holoblastic to meroblastic cleavage permitted an even greater increase in yolk quantity and a larger hatchling size.

One test of this scenario would be to determine whether other reptiles have a yolk sac like that of the corn snake and other squamates mentioned above. A basal phylogenetic distribution would provide strong support for the invasion of cellularized yolk by blood vessels as an ancestral reptilian character. If this scenario seems plausible, the chicken yolk sac with its non-cellularized, liquid yolk becomes a derived condition, requiring an explanation for its origin. One possibility would be the time available for cell divisions within the yolk. Increases in the amount of yolk coupled with decreases in the developmental time to hatching would favor the persistence of liquid yolk. Examination of yolk sac development in a wide range of reptiles will undoubtedly uncover unexpected diversity and permit the historical reconstruction of evolutionary events with significant functional implications.

\section{References}

AGASSIZ, L. (1857). Contributions to the Natural History of the United States of America, First Monograph, Volume II, Part III - Embryology of the Turtle. Little, Brown and Co., Boston.

ARENDT, D. and NÛBBLER-JUNG, K. (1999). Rearranging gastrulation in the name of yolk: evolution of gastrulation in yolk-rich amniote eggs. Mech Dev 81: 3-22.

BELLAIRS, R., LORENZ, F.W., and DUNLAP, T. (1978). Cleavage in the chick embryo. $J$ Embryol Exp Morphol 43: 55-69.

BLACKBURN, D.G. (1995). Saltationist and punctuated equilibrium models for the evolution of viviparity and placentation. J Theor Biol 174: 199-216.

BUCHHOLZ, D.R., SINGAMSETTY, S., KARADGE, U., WILLIAMSON, S., LANGER, C.E., and ELINSON, R.P. (2007). Nutritional endoderm in a direct developing frog: a potential parallel to the evolution of the amniote egg. Dev Dyn 236: 1259-1272.

CHALMERS, A.D. and SLACK, J.M. (2000). The Xenopus tadpole gut: fate maps and morphogenetic movements. Development 127: 381-392.

CLARK, H.J. (1863). A claim for scientific property. Cambridge MA (pamphlet - 3pp)

CLARK, H.J. (1865). Mind in Nature: The Origin of Life, and the Mode of Development of Animals. Appleton \& Co., New York.

COLLAZO, A., BOLKER, J.A., and KELLER, R.E. (1994). A phylogenetic perspective on teleost gastrulation. Am Nat 144: 133-152.

COLLAZO, A. and KELLER, R. (2010). Early development of Ensatina eschscholtzii: an amphibian with a large, yolky egg. EvoDevo 1: 6.

DESNITSKIY, A.G. and LITVINCHUK, S.N. (2014). Comparative and phylogenetic perspectives of the cleavage process in tailed amphibians. Zygote doi:10.1017/ S0967199414000379.

DUFAURE, J.P. and HUBERT, J. (1961). Table de développement du lézard vivipare: Lacerta (Zootoca) vivipara Jacquin. Arch Anat Microsc Morphol Exp 50: 309-328.

ELINSON, R.P. (1989). Egg evolution. In Complex Organismal Functions: Integration and Evolution in Vertebrates (Eds. D.B. Wake and G. Roth). John Wiley \& Sons, Chichester, England, pp. 251-262.

ELINSON, R.P. (2009). Nutritional endoderm: a way to breach the holoblastic-meroblastic barrier in tetrapods. J Exp Zool 312B, 526-532.

ELINSON, R.P. and BECKHAM, Y. (2002). Development in frogs with large eggs and the origin of amniotes. Zoology 105: 105-117.

ELINSON, R.P. and STEWART, J.R. (2014). The corn snake yolk sac becomes a solid tissue filled with blood vessels and yolk-rich endodermal cells. Biol Lett 10:20130870.

GILBERT, S.F. (2010). Developmental Biology, $9^{\text {th }}$ ed. Sinauer Assoc., Sunderland, MA.

HAMILTON, H.L. (1952). Lillie's Development of the Chick: An Introduction to Embryology, 3rd ed. Henry Holt, New York.

IRMSCHER, C. (2013). Louis Agassiz: Creator of American Science. Houghton Mifflin Harcourt, Boston.

JIN, S.W., BEIS, D., MITCHELL, T., CHEN, J.N., and STAINIER, D.Y.R. (2005). Cellular and molecular analyses of vascular tube and lumen formation in zebrafish. Development 132: 5199-5209.

KNIGHT, S.M. and BLACKBURN, D.G. (2008). Scanning electron microscopy of the fetal membranes of an oviparous squamate, the corn snake Pituophis guttatus (Colubridae). J Morphol 269: 922-934.

LEE, H.C., CHOI, H.J., PARK, T.S., LEE, S.I., and KIM, Y.M. et al., (2013) Cleavage events and sperm dynamics in chick intrauterine embryos. PLOS ONE 8: e80631. DOI:10.1371/journal.pone.0080631

LURIE, E. (1988). Louis Agassiz: A Life in Science. Johns Hopkins University Press, Baltimore, Maryland.

MAZUMDAR, A. and MAZUMDAR, M. (2002). How one becomes many: blastoderm cellularization in Drosophila melanogaster. Bioessays 24:1012-1022.

PACKARD, A.S. (1877). Memoir of Henry James Clark, 1826-1873. Read before the National Academy, April 23, 1874. Biographical Memoirs, National Academy of Sciences, 1: 317-328.

PACKARD, M.J. and SEYMOUR, R.S. (1997). Evolution of the amniote egg. In Amniote Origins (Eds. S.S. Sumida and K.L.M. Martin). Academic Press, San Diego, CA, pp. 265-290.

RISAU, W. (1997). Mechanisms of angiogenesis. Nature 386: 671-674

ROMANO, M., ROSANOVA, P., ANTEO, C., and LIMOTOLA, E. (2002). Lipovitellins and phosvitins of the fertilized eggs during embryo growth in the oviparous lizard Podarcis sicula. Mol Reprod Dev 63: 341-48.

ROMANOFF, A.L. (1960). The Avian Embryo; Structural and Functional Development Macmillan, New York

SITES Jr., J.W., REEDER, T.W., and WIENS, J.J. (2011). Phylogenetic insights on evolutionary novelties in lizards and snakes: sex, birth, bodies, niches, and venom. Ann Rev Ecol Evol Syst 42: 227-244.

STEWART, J.R. (1997). Morphology and evolution of the egg of oviparous amniotes In Amniote Origins (Eds. S.S. Sumida and K.L.M. Martin). Academic Press, San Diego, CA, pp. 291-326. 
STEWART, J.R., RUSSELL, K.J., and THOMPSON, M.B. (2012). Development of yolk sac and chorioallantoic membranes in the Lord Howe Island Skink, Oligosoma lichenigerum. J Morphol 273: 1163-1184.

TAKEUCHI, M., TAKAHASHI, M., OKABE, M., AND AIZAWA, S. (2009). Germ layer patterning in bichir and lamprey; an insight into its evolution in vertebrates. Devel Biol 332: 90-102.

VOKES, S.A. and KRIEG, P.A. (2002). Endoderm is required for vascular endothelial tube formation, but not for angioblast specification. Development 129: 775-785.
WEEKES, H.C. (1927). Placentation and other phenomena in the scincid lizard Lygosoma (Hinulia) quoyi. Proc Linn Soc NSW 52: 499-554.

WILT, F.H. (1965). Erythropoiesis in the chick embryo: the role of endoderm. Science 147: 1588-1590.

WINSOR, M.P. (1991). Reading the Shape of Nature: Comparative Zoology at the Agassiz Museum. Univ. of Chicago Press, Chicago.

ZEHR, D.R. (1962). Stages in the normal development of the common garter snake Thamnophis sirtalis sirtalis. Copeia 1962: 322-329.

\section{Further Related Reading, published previously in the Int. J. Dev. Biol.}

Primitive and definitive erythropoiesis in the yolk sac: a bird's eye view.

Guojun Sheng

Int. J. Dev. Biol. (2010) 54: 1033 - 1043

Reptile scale paradigm: Evo-Devo, pattern formation and regeneration

Cheng Chang, Ping Wu, Ruth E. Baker, Philip K. Maini, Lorenzo Alibardi and Cheng-Ming Chuong

Int. J. Dev. Biol. (2009) 53: 813-826

The morphogenesis of evolutionary developmental biology

Scott F Gilbert

Int. J. Dev. Biol. (2003) 47: 467 - 477

The place of phylogeny and cladistics in Evo-Devo research

Maximilian J Telford and Graham E Budd

Int. J. Dev. Biol. (2003) 47: 479 - 490

Origin and evolution of endoderm and mesoderm.

Ulrich Technau and Corinna B Scholz

Int. J. Dev. Biol. (2003) 47: 531 - 539

5 yr ISI Impact Factor $(2013)=\mathbf{2 . 8 7 9}$
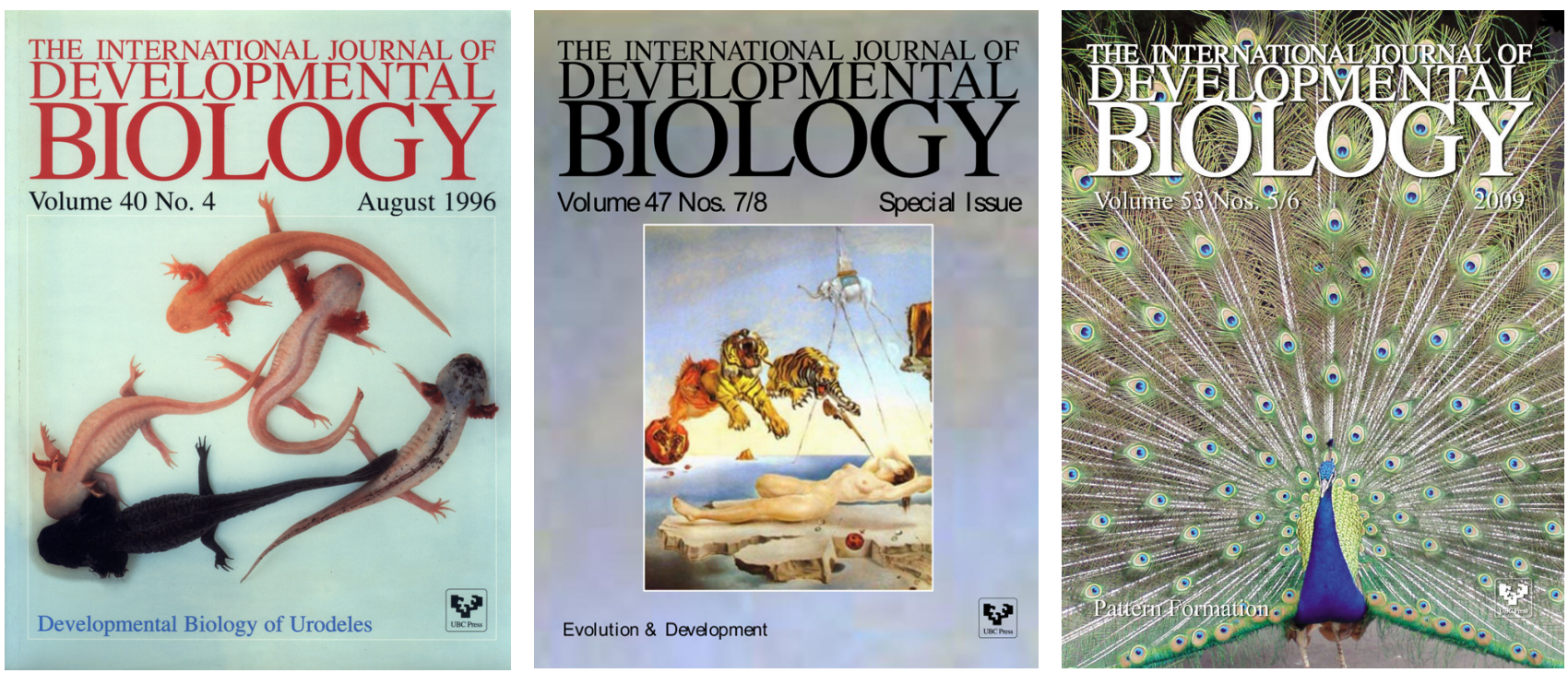